\title{
Foresight technology in the integration of education, science and production
}

\author{
Saule Sagintaeva ${ }^{1}$, Rinat Zhanbayev ${ }^{1}$, and Anton Nazarov²* \\ ${ }^{1}$ Almaty University of Power Engineering and Telecommunications named after Gumarbek Daukeev, \\ Baytursynuli 126/1, Almaty, Republic of Kazakhstan \\ ${ }^{2}$ Ural State University of Economics, 8 Marta / Narodnoy Street 62/45, 620000 Yekaterinburg, \\ Russian Federation
}

\begin{abstract}
One of the most pressing problems in modern conditions for the state is forecasting scientific and technological development with the definition of promising strategic directions and innovative technologies. Such forecasting or scientific foresight is necessary for the successful political, economic and social development of the state. Foresight technology is a tool in choosing long-term priorities for the country's development, which will help determine strategic research directions and new technologies that contribute to the greatest socio-economic effect and the integration of education, science, and production. The article describes the approach developed by the authors, which is to recognize the priority of the development of regional science, which makes it possible to use the potential of university and industry science directly at the locations of production structures. In this regard, the authors substantiate the need to form a mechanism for interaction between higher education and business, which is based on the "triple helix" model, modified taking into account the specifics of mono-industrial regions. With the help of the mechanism proposed by the authors, based on the adapted model of the "triple helix", in which the university plays a system-forming role, the problems of single-industry towns can be solved. Itmotivateslocal businesses to create and implement innovative projects using the scientific potential of the regional university.
\end{abstract}

\section{Introduction}

The transition of the economy of Kazakhstan to a new stage of development is directly related to the increasing role of theoretical knowledge, the development of high-tech industries, and the influence of IT technologies. An important place in creating new conditions for economic development is given to the education system. As the study showed, most educational technologies operate in an inertial mode, without taking into account modern realities and the needs of the economy and society. The authors of the study are convinced that learning should be future-oriented, i.e. - should teach to predict and stay ahead of modern advances in science and technology. The study proposes to

\footnotetext{
${ }^{*}$ Corresponding author: nazarovad@,usue.ru
} 
overcome these contradictions to form a stable systemic connection between specific sectors of the economy and higher education.

To choose a strategy for the further development of the country, it is necessary to create an effective tool for the exchange of information between the business community, industrial organizations, government agencies, and educational institutions. Cooperation and interaction of these organizations will allowus to determine the strategic directions of research and select new technologies that contribute to the greatest socio-economic effect. According to the authors, the best tool for assessing the long-term prospects of science, technology, economy, and society is foresight technology, which has proven itself in many countries of the world $[1,2]$.

The main idea of foresight is to determine and select the strategic directions of science, technology, economy, social sphere, and other spheres of state life, which is 15-20 years will become decisive for the development of an individual state and the entire world community. Foresight research requires the involvement of a large number of experts to develop integrated solutions at the intersection of different scientific fields, types of economic activity, and the competence of officials and organizations.

The purpose of this study is to determine the possibility of using foresight methods in ensuring the integration of education, science, and production. Research area: the use of foresight methods in the development of new information technologies that ensure the emergence of points of scientific and technical growth, influencing the choice of promising areas of scientific and technical activity and based on the formation of a university environment with a high degree of communication. As a result, a systemic dialogue between production and higher education should be established.

The specific objectives to achieve this purpose are as follows:

1. Creation of a methodological basis for the integration of foresight methods into the educational process, including bringing educational and methodological documentation in master's and doctoral studies by the requirements of the time, including the need to increase the communication connectivity of the scientific and educational space and the creation of points of scientific and technological growth;

2. Development and implementation into practical use in an experimental mode of new information technologies that ensure the integration of foresight methods into the educational process;

3. Creation of forms of educational work based on the use of the integration of foresight methods into the educational process, clear evidence of their effectiveness as a method of stimulating scientific and technical activities, and commercializing the results.

\section{Materials and methods}

The study used the foresight method, which allows determining in the best way the promising directions of the development of science. The methods of bibliometrics, scientometrics, patent analysis, observation and collection of facts, modeling methods were also used.

Bibliometric analysis, or the method of counting the number of publications, involves a quantitative assessment of the document flow and quantitative analysis of scientific documents from different fields of knowledge. According to the results of bibliometric analysis, fields of science and individual sections are distinguished, which, in terms of the number of scientific publications, occupy a leading place in the structure of scientific knowledge [3].

Scientometrics, or citation analysis, is carried out by examining bibliographic references in publications of databases of scientific periodicals (Web of Science, SCOPUS, TR) to 
identify the citation of publications that form a certain direction of science, the number of references (self-citation is excluded), the total number of publications in the direction [4 ].

In the patent analysis, statistical methods are used for processing patent information arrays, which include the analysis of the curves of the dynamics of inventive activity for each scientific and technical direction; the result of the analysis is to build a cumulative series of patented, characterized by an increase in the total number of patents related to this area [5].

Empirical general scientific methods of cognition were used to study the state of educational programs and scientific work at universities. The method of observation and collection of facts, which consists in the purposeful perception of processes in their real form, made it possible to study the current state of research and innovation activity in the region, to identify existing problems. The modeling method was applied to form the approach, the core of which is the "triple helix" model, taking into account the specifics of inequality of regions, which consists of the decomposition of regions according to the degree of depression. This methodological approach is quite capable of providing a flexible response associated with a change in the status of partners in the "triple helix" model. [6].

\section{Results}

During the first task, taking into account the need to increase the communication connectivity of the scientific and educational space and create points of breakthrough scientific and technical growth, scientifically grounded methodological foundations of specific forms of reporting by scientific leaders of undergraduates and doctoral students have been created, which allow effective use of foresight methods. The purpose of such forms is to minimize the time spent by experts from the domestic business community and foreign academic circles in making an opinion on the significance of a particular study for the domestic economy. This provides an opportunity to attract a wide range of experts to make conclusions [7, 8].

The principle of conjugation with the methods of psychological testing and the sociological survey was used for the first time in the forms of reporting on the work on master's and doctoral dissertations, which made it possible to conclude the conscientiousness of respondents (both scientific advisers and experts). Optimized methods of questioning scientific leaders have been developed using elements of psychological and sociological testing [9].

When performing the second task, to obtain results in the practical use of the experimental mode of new information technologies, mathematical algorithms were developed based on methods previously used for psychological testing and sociological surveys, and software tools were developed to process the obtained data.

The use of foresight methods in the educational process as a system of methods for expert assessment of strategic prospects for innovative development and identification of technological breakthroughs that can have the maximum impact on the economy and society in the medium and long term, allowed the authors to develop an algorithm [10].

The developed new algorithm provides quantitative assessments of the significance and relevance of scientific and scientific and technical projects, dissertations and other scientific and technical materials based on the discussion on a digital discussion platform, based on the principles of fuzzy logic; also developed an accompanying methodology for calculating the basic parameters [11].

This algorithm made it possible to use the existing intellectual potential as efficiently as possible to solve urgent problems facing the national economy and to develop ways of commercializing the results of scientific and technical activities.

The proposed approach solves the following tasks: 
- improving the quality of training for undergraduates and doctoral students through constant effective control over the implementation of dissertations;

- creation of a discussion platform designed to discuss the progress of the dissertation work and identify shortcomings based on the principle of mutual (peer) review during an open discussion.

An event was organized to prepare experimental information, where the reports of the heads of $1^{\text {st }}$-year doctoral students of the Almaty University of Power Engineering and Telecommunications were heard. The assessment of the presented topics of theses was carried out according to the selected criteria, that is, in practice, new experimental information technologies were used to ensure the interface of foresight methods with the educational process.

The third task resulted in the development of mathematical and logical software algorithms for the server part of the data distribution and processing system. The developed mathematical and logical algorithms for the system of on-line processing and data mining, using fuzzy logic, which can improve the efficiency of the process of working with data. The basis of the created system is a mathematical data model, made using the theoretical foundations of fuzzy logic, and an OLAP-model for their processing. The data processing layer consists of the following applications:

1. Ensuring the operation of server software for the implementation of technology that does not have a user interface.

2. Formation of analytical information for its use by various technology applications [12].

The results obtained, based on the developed algorithm and the form of expert assessment, made it possible to create an informational discussion platform that allows for a high-quality examination of the results of scientific activity to increase the practical significance. The foresight method proposed by the authors as the most optimal tool for choosing priority areas of science and technology is clear evidence of the method of stimulating scientific and technical activity and commercializing its future results.

The listed capabilities allow integrating foresight technology into the research process.

This study complements the theory and practice of foresight as a forecasting technology with the following:

- allows evaluating, compare, and summarize the results of a large number of different strategic studies on the issue under consideration;

- helps to identify points of growth of the economy to assess potentially promising commercially profitable activities in the business environment;

- provides systematic constructive interaction between representatives of science (undergraduates, doctoral students, professors) and the expert community to identify and develop promising areas of scientific and technical activities;

- corrects the progress of research work in terms of commercialization of scientific and technical activities;

- reduces labor costs and increases efficiency in identifying and considering promising topics for scientific works of undergraduates, doctoral students, professors, and also provides a stable systemic connection between specific sectors of the economy and higher education $[13,14]$.

As a result of the research, a software system was developed that is designed to automate the data processing process. The system allows for data mining, retrieving missing data, increasing the processing speed and convenience of presenting data to the end-user in comparison with classical methods [15].

In the course of the study, the experimental implementation of the developed information technology "Forsite" in the educational process of training undergraduates and doctoral students, the development of administrative procedures with the involvement of 
experts and students was carried out. Trial testing was carriedout using a small number of projects. The web application (information system) has been implemented in the NJSC "Almaty University of Power Engineering and Telecommunications". The results of the introduction of the developed information technologies into the educational process are generalized, the algorithms and software used are corrected. The experimental decisionmaking algorithm is positioned as an environment for the development of informationanalytical systems to support the assessment and decision-making process. The technology supports all decision-making processes, from data collection to the automatic search for problematic trends in the simulated domain.

\section{Conclusion}

As a result of the created information discussion platform as a tool, a new attempt was made to achieve information exchange between the scientific and business communities, industrial organizations, and other domestic structures that can select and formulate the tasks that need to be solved for the accelerated innovative development of the national economy.

As a result of the study, the existing foresight technology designed to identify the most promising areas of scientific and technical activities, aimed at ensuring the correction of the progress of master's and Ph.D. theses to increase their economic efficiency, including in terms of commercializing the results of scientific and technical activities, has been modernized.

The research results provide the creation of new forms of stimulating scientific and technical activities aimed at mobilizing such a resource as the labor costs of undergraduates and doctoral students in the learning process. Until now, this resource (if we talk about a direct contribution to the economy of the Republic of Kazakhstan) remains unused: the number of master's or Ph.D. dissertations that led to the creation of start-up companies (or to commercially significant use in other forms) does not exceed $1 \%$ of their total number [16].

Moreover, the research results represent a unique experiment in the field of institutional economics, aimed at the directed creation of an institution that provides the identification of the most promising research areas in the mode of self-organization [16].

Raising the level of scientific and technical activities, establishing high communication in the scientific community allows and ensures systematic dialogue interaction between sectors of the economy and higher education, which, as a result, will give a great impetus to the integration of education, science, and production. The identification of new strategic scientific directions and technological advances in the long term will have a significant impact on the socio-economic development of the state and society [17].

Within the framework of the project, an analysis carried out at the regional level revealed that scientific research in universities is conducted in different directions, which is necessary for a diverse economy. We believe that it is necessary to create a regional research and production center, contributing to the formation of such a scientific potential, which would activate the construction of an innovative economy in the region. We have shown this by the example of the Zhezkazgan region based on the "triple helix" model, which assumes the interaction of science, education, and production.

The authors have developed an approach to the formation of the mechanism of interaction between higher education and business, which is based on the model of the "triple helix" modified taking into account the specifics of mono-industrial regions.

The versatility of the model and the proposed mechanism lies in the fact that it solves 
problems and satisfies the needs of all participants. Universities get the opportunity to orient their educational programs to employers' requests while combining educational and scientific activities. This will affect the quality indicators of training specialists for the industry of a monotown, their purposeful preparation for production. Regional business receives a significant impetus and motivational effect, which immediately acquires an innovative charactersince it is tied into a single system of relationships with science based on a local university and a city-forming enterprise.

We believe that the results of this study can be developed to measure the general level of training of scientific personnel in the region and conditions for growth.

\section{References}

1. S.S. Sagintaeva, R.A. Zhanbaev, A.Sh. Abildina, Vestnik Almatinskog ouniversiteta jenergetiki i svjazi, 3(42) (2018)

2. S.S. Sagintaeva, R.A. Zhanbaev, A.Sh. Abildina, Vestnik NIA RK, 2 (2019)

3. O.I. Voverene, NTI. Ser. 1, 7 (1985)

4. V.V. Nalimov, Z.M. Mulchenko, Scientometrics. Study of the development of science as an information process (1969)

5. Je. P. Skornjakov, T. B. Omarova, O. V Chelysheva, Guidelines for conducting patent research (2000)

6. L. Leydesdorff, I. Ivanova, J. of Open Innovation Technology Market and Complexity, 2 (2016)

7. G. Shvajcer, E. M. Merser, Foresight, 1(2) (2007)

8. V.N. Postnikov, Science and education, 5 (2012)

9. M. G. Semenenko,S. I. Chernjaev, The successes of modern natural science, 3 (2014)

10. I.V. Shostak, M.A. Danova, Ju.A. Romanenkov, Communal economy mist, 123 (2015)

11. P.I. Bidjuk, A.S. Gasanov, S.E. Vavilov, System research and information technology, 4 (2013)

12. I.I. Pospelova, L.A. Lotov, Multicriteria problems of decision-making (2008)

13. E. Tapinos, N. Pyper, Tech. Forecasting and Social Change, 126 (2018)

14. C.A. Bastos, Tech. Forecasting and Social Change, 128 (2018)

15. I. Suleimenov, O. Gabrielyan, G. Mun, S. Panchenko, T. Amirzhan,K. Suleimenov, Int. J. on Communications, 3 (2014)

16. I. Je. Sulejmenov, Educational resources and technologies, 2 (19) (2017)

17. R. Danell, O. Persson, Scientometrics, 58 (2) (2003) 